\title{
A realidade da caprinocultura e ovinocultura no semiárido brasileiro: um retrato do sertão do Araripe, Pernambuco
}

\author{
Rafael Santos de Aquino ${ }^{*}$, Celma Gomes de Lemos$^{2}$, Clerisvaldma Alves Alencar², \\ Edmilson Gomes da Silva ${ }^{3}$, Rodrigo da Silva Lima ${ }^{3}$, Jose Almir Ferreira Gomes ${ }^{3}$, Almir \\ Ferreira da Silva ${ }^{4}$ \\ ${ }^{1}$ Professor - Instituto Federal do Sertão Pernambucano (IF Sertão-PE), - Campus Ouricuri, Departamento de \\ Agropecuária, Ouricuri, Pernambuco, Brasil. rafael.aquino@ifsertao-pe.edu.br \\ ${ }^{2}$ Aluna do Instituto Federal do Sertão Pernambucano (IF Sertão-PE) - Campus Ouricuri, Ouricuri, \\ Pernambuco, Brasil. Estrada do Tamboril, s/n, Ouricuri -PE. 56.200-000. celma4569@hotmail.com; \\ clerisalves28@hotmail.com \\ ${ }^{3}$ Professor - Instituto Federal do Sertão Pernambucano (IF Sertão-PE), Campus Salgueiro, Departamento de \\ Agropecuária, Salgueiro, Pernambuco, Brasil.edmilsonzoo@gmail.com; rodrigo.lima@ifsertao-pe.edu.br; \\ ${ }^{4}$ Zootecnista, Gerente de Produção da MULTICAMP LTDA. Bezerros, Pernambuco, Brasil. \\ *Autor para correspondência \\ Trabalho desenvolvido pela equipe de pesquisa de Agropecuária do Instituto Federal do Sertão Pernambucano, \\ com a colaboração da Multicamp Ltda. e Acocama.
}

RESUMO. Este trabalho foi realizado entre dezembro de 2011 e janeiro de 2012 pela ação de cooperação técnica entre o Instituto Federal do Sertão Pernambucano, Campus Ouricuri e a Associação de Criadores de Ovinos e Caprinos da Microrregião do Araripe (ACOCAMA), e objetivou avaliar o perfil dos caprino-ovinocultores dos municípios de Ouricuri-PE e Santa Filomena-PE associados à ACOCAMA. Após aplicação de questionário como ferramenta de verificação das condições produtivas e de manejo utilizadas pelos produtores pôde-se constatar que apesar da associação produtiva as técnicas de manejo continuam tradicionais e a principal forma de valorização econômica se deu através de programas governamentais como o PAA (Programa de Aquisição de Alimentos) e o PNAE (Programa Nacional de Alimentação Escolar). Os produtores não produzem apenas caprinos e ovinos, mas também bovinos e culturas agrícolas temporais, não contam com assistência técnica especializada e atuam com técnicas de manejo tradicionais.

Palavras-chaves: associativismo, nordeste, pecuária.

\section{The reality of sheep and goat production in Brazilian Semiarid: a picture of Araripe Sertao, Pernambuco}

\begin{abstract}
This work was carried out between December 2011 and January 2012 through technical cooperation action between the Federal Institute of Pernambucan Sertao, Campus Ouricuri, and Association of Producer of Sheep and Goats of the Microregion of Araripe (ACOCAMA in Portuguese), and aimed to evaluate the profile of goat and sheep farmers in the municipalities of Ouricuri-PE and Santa Filomena-PE associated with ACOCAMA. After a questionnaire as verification tool of production conditions and management applied by producers it could be seen that despite the productive association management techniques remain traditional and the main form of economic valuation was made through government programs such as PAA (Program Food Acquisition) and PNAE (National School Meals Program). Producers produce not only goats and sheep but also cattle and temporal crops, do not have specialized technical assistance and work with traditional management techniques.
\end{abstract}

Keywords: associativism, Northeast, livestock. 


\section{Introdução}

A caprino e a ovinocultura desenvolveram-se gradativa e pontualmente no território brasileiro em que segundo Jainudeen et al. (2004) foram os primeiros a serem introduzidos no Brasil juntamente com outras espécies como os bovinos, trazidos por colonizadores portugueses para o Nordeste à quase cinco séculos, mais precisamente em torno de 1.535 .

Os fatores históricos e geoclimáticos no Nordeste foram determinantes para a pujança da caprino e ovinocultura, mesmo que rudimentar, pois segundo a FAO (2015) encontra-se, nesta região, 92\% do rebanho caprino nacional; porém, apesar disso, a criação de caprinos na região semiárida brasileira é caracterizada por práticas de manejo inadequadas, relacionadas principalmente aos aspectos sanitários, onde segundo Sotomaior et al. (2007) apresenta altas taxas de mortalidade e morbidade causando prejuízos econômicos aos produtores.

Segundo a opinião de criadores, um dos fatores que mais limita a criação empresarial de caprinos são os problemas sanitários, a falta de crédito rural e de pastagem cultivada entre outros (Oliveira et al., 1995), baixas taxas de desfrute em virtude de falhas no manejo, principalmente sanitário, são relatadas há décadas em vários Estados, como Pernambuco (Araújo Filho et al., 1999).

Para Gouveia (2003), a caprinocultura brasileira divide-se em dois segmentos distintos: o tradicional, de grande importância social, e o tecnificado, de importância econômica, mais moderno e produtivo mostrando-se como agronegócio para produção de carne, leite e pele. A maioria dos produtores do semiárido, carecem de conhecimento especializado para potencializar a produção com técnicas apropriadas ao manejo de sequeiro, e acabam atuando em nível de subsistência.

O estado de Pernambuco divide-se geograficamente em três sub-regiões: Litoral/Mata, Agreste e Sertão. Esta última está subdividida em duas mesorregiões (Sertão Pernambucano e São Francisco Pernambucano). Os municípios de Santa Filomena e de Ouricuri fazem parte da microrregião do Sertão do Araripe ou de Araripina, localizada no oeste setentrional de Pernambuco, sendo composta por mais nove municípios, Araripina, Trindade, Ouricuri,
Bodocó, Exu, Granito, Moreilândia, Ipubi e Santa Cruz.

A região estudada caracteriza-se por apresentar hegemonicamente, solos rasos e jovens, e clima semiárido, com chuvas escassas e concentradas entre 3 a 4 meses do ano (Prado, 2003).

Um dos caminhos para a melhoria do setor caprino-ovinocultor é a formação e o fortalecimento de associações e cooperativas de criadores, que passam a suprir necessidades individuais a partir das diferenças coletivas e proporcionam, ou devem proporcionar, dessa forma, a implementação da melhoria produtiva dos associados, já que a interdependência e a ação organizacional reduzem a dependência por recursos individuais e ampliam a dependência dos recursos coletivos (Kunzller \& Bulgacov, 2011).

De acordo com Costa et al. (2011), as associações de pequenos produtores e trabalhadores rurais, assim como os conselhos municipais de desenvolvimento rural mostram-se como novas formas de agregação social que coexistem com outras categorias, como os grupos de interesse e os sindicatos, com uma função de socialização e se constituem, hoje, como novos canais de participação e de representação.

Ocorre no nordeste, principalmente na região semiárida uma tendência de aumento no agronegócio da produção animal em relação à agropecuária de sequeiro (Silva et al., 2004). Esta substituição tem sido feita principalmente, pela pecuária leiteira e caprina e ovinocultura (Araújo Filho et al., 1999).

Um dos fatores pelo qual a caprino e ovinocultura tradicional nordestina peca é no planejamento forrageiro, principalmente no tocante à convivência com a seca, pois ainda há muitos produtores que não realizam adequadamente o cultivo de forrageiras importantes à região, não realizam a produção de silagens e feno de acordo com as recomendações técnicas para obter um alimento mais nutritivo, não planejam o aproveitamento das sobras de forragem e desconhecem formas de cultivos agroecológicos que possibilitam aperfeiçoar a produção de maneira sustentável e possibilitando melhor convivência com o semiárido.

Dessa forma, o objetivo do trabalho foi pesquisar e analisar o perfil dos produtores de caprinos e ovinos da Associação dos Criadores de 
Ovinos e Caprinos da Microrregião do Araripe (ACOCAMA) nos municípios de Santa Filomena e Ouricuri no Estado de Pernambuco.

\section{Material e Métodos}

Trabalho realizado pela equipe de Pesquisa Zootécnica do Curso Técnico em Agropecuária do Instituto Federal do Sertão Pernambucano, Campus Ouricuri, juntamente com a ACOCAMA, frente a acordo de cooperação técnica entre si, pelo qual ocorreram dois estágios supervisionados obrigatórios.

\section{Pesquisa de campo}

Foi realizada pesquisa de campo no período de 12 de dezembro de 2011 a 24 de janeiro de $2012 \mathrm{em}$ que visitadas 52 propriedades (27 em Santa Filomena e 25 em Ouricuri) aplicou-se um questionário avaliativo sobre o perfil produtivo de produtores de caprinos e ovinos associados à ACOCAMA, em para conhecer as condições produtivas e de capacitação técnica dos produtores e da ação articuladora da associação frente ao fortalecimento econômico e social dos seus produtores.

Buscou-se a obtenção de informações a respeito da identificação dos produtores, da área produtiva, do tipo de titularidade da propriedade (se é o dono, arrendatário ou parceiro); levantamento do suporte forrageiro (tipo de pastagem, manejo do solo, determinação de fertilidade do solo, utilização de capineiras, banco de proteína, espécies cultivadas, alimentação no cocho); produtividade agropecuária (quais são as culturas animais e vegetais predominantes, formas de comercialização, principais dificuldades produtivas etc.).

Foi realizada também pesquisa bibliográfica para elucidação e discussão dos resultados encontrados, sendo utilizadas as principais plataformas de consulta às referências bibliográficas aplicadas de acesso livre na Internet.

\section{Fertilidade de solo}

Foram realizadas análises de fertilidade de solo para confrontação com os resultados referentes aos dados de produção de forragem em quatro propriedades, sendo duas em Ouricuri e outras duas em Santa Filomena, as quais foram denominadas como: Propriedades A, B, C e D, a fim de facilitar a compreensão da análise. A
Propriedade A foi dividida em três subáreas (Subárea A1, Subárea A2 e Subárea A3), pois a mesma apresentava área muito extensa e características diversas, como, topografia bastante acidentada, solo com cores distintas, onde já haviam sido cultivados melancia, feijão e milho, utilizando adubação química. As demais propriedades apresentavam-se uniformes quanto às características observadas.

A metodologia empregada foi de acordo com o Manual de Recomendação de Adubação para o Estado de Pernambuco (EMBRAPA, 2006). As análises foram realizadas no laboratório de análise de solo da EMBRAPA Semiárido, localizada na BR 428, Km 152, Zona Rural Petrolina, PE.

\section{Estatística}

A análise dos dados foi realizada com auxílio do software Microsoft Excel, 2007, do Pacote Office do Windows 7, e foram calculados os valores de frequência para caracterizar o perfil produtivo básico dos associados da ACOCAMA e confecção de gráficos e tabelas.

\section{Resultados e Discussão}

A ACOCAMA é uma associação que envolve vários municípios da região do Sertão do Araripe e está em funcionamento desde 2001. Conta com o auxílio de alguns programas de apoio ao trabalhador rural, como o Pró Rural (Programa Estadual de Apoio ao Pequeno Produtor Rural), Pronaf (Programa Nacional de Fortalecimento da Agricultura Familiar), Programa de Aquisição de Alimentos (PAA) e o Programa Nacional de Alimentação Escolar (PNAE), como principais fontes de fortalecimento econômico e social dos associados, em 2012 contava com 434 associados.

$\mathrm{O}$ associativismo rural produtivo geralmente tem tido forte apoio do Estado, onde o Programa Nacional de Fortalecimento da Agricultura Familiar (Pronaf) e outros, de empréstimos e incentivos para agricultores geridos por bancos públicos e de fomento, optam por canalizar seus recursos para associações de produtores e agricultores.

Em Santa Filomena 88\% eram donos legais do imóvel rural, $12,0 \%$ eram posseiros. Em relação à presença de recursos hídricos rurais $44,44 \%$ possuíam ao menos um açude na propriedade e 55,6\% apresentam ao menos um barreiro. 
Em Ouricuri 95\% eram donos da propriedade e apenas 5\% eram posseiros. Ao menos um açude era encontrado em $63 \%$ das propriedades e ao menos um barreiro em $37 \%$ delas.

No total $91,5 \%$ dos associados são donos da propriedade e apenas $8,5 \%$ eram posseiros e $53,7 \%$ possuem pelo menos um açude e $47,3 \%$ tem um barreiro no mínimo.

Segundo os produtores um fator limitante na produção agropecuária é a falta de máquinas agrícolas para o preparo do solo no período de implantação das culturas e mais apoio na comercialização e produção em geral. A associação dispõe de algumas máquinas agrícolas, como forrageira, ensiladeira e motores bomba para irrigação que são em alguns casos compartilhadas equitativamente entre os associados por um período de tempo para ajudar e facilitar na produção, porém, o número de máquinas ainda é pequeno e não dá para todos os associados.

A ACOCAMA não tem nenhum profissional capacitado na administração e produção rural como administrador, zootecnista, veterinário ou agrônomo. Tais profissionais são contratados para serviços temporários e pontuais de acordo com a necessidade momentânea. A ausência de profissionais das Ciências Agrárias no quadro de profissionais permanentes da associação dificulta e atrasa o processo de evolução produtiva da caprino e ovinocultura nordestina, já que impossibilita a assistência técnica constante.

Apesar de cometer falhas estratégicas e administravas a ACOCAMA contribui para o crescimento econômico e social dos caprinos e ovinocultores da região do Araripe, fixando-os no campo. Araújo (2003) quando afirmou que a organização do segmento agropecuário tem como característica típica um grande número de produtores rurais, predominantemente pequenos, distribuídos e distanciados em grandes espaços com pouca organização representativa, de modo que não possuem capacidade suficiente para formar o preço de seus produtos.

\section{Produção Animal}

De acordo com o levantamento realizado, o total de animais registrados entre os associados da ACOCAMA nos dois municípios, foi de 1.964 compreendendo as espécies caprina (451 cabeças), ovina (1.346 cabeças) e bovina (167 cabeças); O rebanho de ovinos apresentou 592 matrizes, 35 reprodutores e 719 animais nas fases de cria, recria e engorda, totalizando os 1.346 ovinos, já o rebanho caprino apresentou 167 matrizes, 13 reprodutores e 271 animais nas fases de cria, recria e engorda, totalizando 451 caprinos. O rebanho bovino divide-se em 70 matrizes, 10 reprodutores e 87 cabeças nas fases de cria, recria e engorda. Os valores percentuais destes dados podem ser verificados na Figura 1.

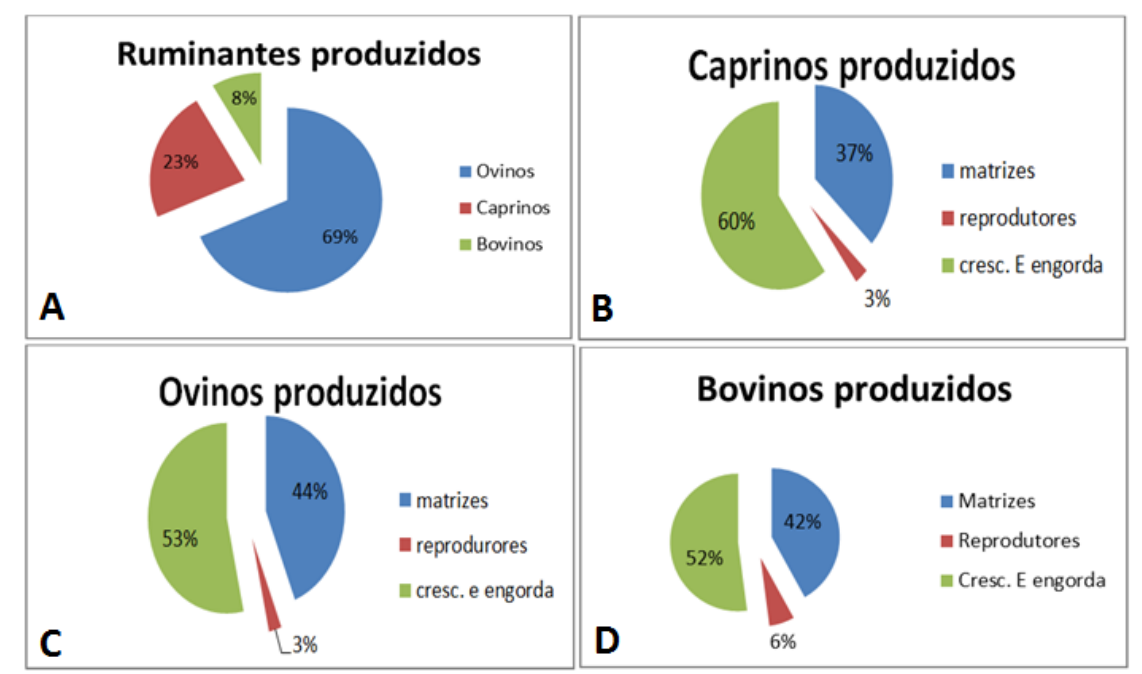

Figura 1 - Distribuição percentual de espécies ruminantes produzidas. (A) distribuição percentual entre as espécies ovina, caprina e bovina; (B) distribuição percentual das categorias animais dentre os caprinos; (C) distribuição percentual das categorias animais dentre os ovinos; e (D) distribuição percentual das categorias animais dentre os bovinos. 
Apesar dos produtores estarem associados a uma associação de criadores de caprinos e ovinos, criam bovinos, que correspondem a $15 \%$ dos animais dos associados de Ouricuri e 8\% dos animais dos associados de Santa Filomena. Ouricuri possui um maior número de caprinos (54\%) do que Santa Filomena (23\%) que em contra partida apresenta uma maior percentual de ovinos, correspondente a $69 \%$ dos animais criados, possivelmente pela influência da ovinocultura forte de Dormentes - PE, município vizinho.

A pluralidade produtiva dentre os pequenos caprino e ovinocultores associados revela a antiga prática da subsistência, que pode ser verificada, por exemplo, no fato de inexistir especialização em determinada cultura, como na criação de caprinos e ovinos.
Delgado (2004) afirmou que o setor de subsistência é quase sempre definido negativa ou residualmente, supostamente porque não é núcleo estruturante da economia; não possui dinâmica própria, mas depende da grande lavoura; e situase à margem da economia dirigida aos mercados - e esta inexoravelmente tenderia a absorvê-lo e dominá-lo.

A diversidade produtiva verificada entre os associados é uma prática atrativa por proporcionar equilíbrio econômico à unidade familiar rural situada à periferia econômica e de impacto local, evidenciando o tradicionalismo histórico da bovinocultura em uma região em que os ovinos e principalmente os caprinos apresentam maior adaptação, quando comparados com a espécie bovina, visivelmente perceptível por estar na região nordeste a maior parcela da população desses animais.

Tabela 1 - Número de categorias animais e principais relações entre categorias para o acompanhamento zootécnico de espécies ruminantes dentre os caprino e ovinocultores associados à ACOCAMA nos municípios de Santa Filomena e Ouricuri, em Pernambuco.

\begin{tabular}{|c|c|c|c|c|c|c|}
\hline Cidades & $\begin{array}{c}\text { Espécies } \\
\text { Ruminantes }\end{array}$ & Matrizes & Reprodutores & $\begin{array}{l}\text { Animais nas } \\
\text { fases de cria, } \\
\text { recria e } \\
\text { engorda }\end{array}$ & $\begin{array}{c}\text { Relação de } \\
\text { Matrizes: } \\
\text { Animais }\end{array}$ & $\begin{array}{l}\text { Relação de } \\
\text { reprodutores: } \\
\text { matrizes }\end{array}$ \\
\hline \multirow{3}{*}{$\begin{array}{l}\text { Santa } \\
\text { Filomena }\end{array}$} & Caprino & 167 & 13 & 271 & $1: 1,70$ & $1: 12,84$ \\
\hline & Ovino & 592 & 35 & 719 & $1: 1,27$ & $1: 16,90$ \\
\hline & Bovino & 70 & 10 & 87 & $1: 1,38$ & $1: 70$ \\
\hline \multirow{3}{*}{ Ouricuri } & Caprino & 352 & 8 & 388 & $1: 1,12$ & $1: 44$ \\
\hline & Ovino & 217 & 12 & 198 & $1: 0,96$ & $1: 18,08$ \\
\hline & Bovino & 87 & 8 & 104 & $1: 1,29$ & $1: 10,87$ \\
\hline
\end{tabular}

Segundo o Conselho Estadual de Política Ambiental (COPAM-MG, 2004) em uma propriedade rural uma matriz ruminante equivale a dez cabeças de animais. E segundo Oliveira et al. (2006) a proporção de machos e fêmeas numa criação extensiva de caprinos e ovinos é de 1 macho para cada 50 fêmeas. Dessa maneira podese verificar na Tabela 1 , que a apenas a proporção de caprinos dos criadores do município de Ouricuri estão mais próximos ao atendimento do índice zootécnico da proporção de fêmeas para um macho em produção extensiva e que as proporções entre reprodutores e matrizes está baixíssima, típica de produção intensiva que deve ser de 2 a 3 machos para 1 fêmea. A proporção de matrizes para as demais categorias animais de produção estão abaixo do que se preconiza que é de dez cabeças animais para cada matriz. Estes dados evidenciam desequilíbrio produtivo, como falta de manejo adequado no que diz respeito à sanidade, reprodução, nutrição e produção.

Uma razão de matriz vs. animais de aproximadamente $1: 1$, revela que a produtividade está aquém de pretensões comerciais e com frágil planejamento rural, e de acordo com os baixos índices produtivos de uma produção extensiva. Corroborando com resultados encontrados por Silva et al. (2004) em estudo realizado na Microrregião do Sertão Paraibano, onde constatou que o sistema de criação adotado era o extensivo $(83,3 \%)$ seguido de semi-extensivo $(16,7 \%)$. Pinheiro et al. (2000) encontraram 
$77,9 \%$ com regime extensivo, $19,6 \%$ do tipo semi-intensivo no estado do Ceará. Pedrosa et al. (2003), que concluiu que o tipo de regime de criação adotado pela maioria dos criadores de caprinos no Rio Grande do Norte é o extensivo.

Nas propriedades visitadas os criadores não realizam todas as práticas de controle zootécnico, na maioria delas a escrituração não existe, mesmo sendo fundamentais para facilitar o manejo do rebanho, apenas é realizada a identificação dos animais com brincos ou com cortes nas orelhas, mas sem nenhum controle que não seja a memória do produtor. Para Medeiros et al. (1994), a identificação das crias com cortes nas orelhas não permite a individualização dos animais e inviabiliza-se o registro de ocorrências específicas como ganho de peso, parto ou cobertura, diferentemente de outros métodos, como uso de brincos, tatuagens e coleiras numeradas, que facilitam o manejo e o acompanhamento personalizado do desempenho animal, presentes em propriedades mais organizadas. Quando os animais adquirem $18 \mathrm{~kg}$ ou idade de 06 a 12 meses está pronto para o abate.

Para um melhor desenvolvimento desta atividade, a ACOCAMA deveria fornecer um funcionário, profissional da produção animal, para fazer o acompanhamento do rebanho ou instruir o próprio produtor para realizar esta atividade, visto que esta é uma tarefa simples e qualquer pessoa alfabetizada pode fazê-la, basta apenas um treinamento inicial.

Em relação ao manejo sanitário a maioria dos associados desvermina os animais três vezes ao ano, sendo que o mais indicado seria realizá-la por quatro vezes ao ano, uma no período chuvoso e três no período seco (Costa et al., 2011) e vacina o rebanho contra febre aftosa duas vezes ao ano conforme programa de ação da ADAGRO (Agência de Defesa Agropecuária de Pernambuco). Alguns também vacinam o rebanho contra carbúnculo sintomático, raiva e tuberculose. A linfadenite caseosa é uma doença comum na região e de difícil controle, limita-se apenas ao tratamento do caroço com falhas no procedimento, como o tratamento inadequado dos resíduos, que favorecem a disseminação da doença no ambiente.

A cura do umbigo nos animais recémnascidos é uma prática simples que favorece a saúde dos animais jovens evitando doenças, mas não é realizada por nenhum produtor. Havendo, inclusive, resistência para isso sob a justificativa do nascimento e crescimento dos animais saudáveis na natureza.

As instalações existentes são basicamente currais simples, feitos de varas com algumas divisórias para cabritos, possuem pequenas coberturas com palhas e telhas. Os cochos e bebedouros são de PVC e de madeira, alguns usam também pneus como cocho que são colocados fora da instalação, porém, não são higienizados. Segundo Olander et al. (1989) o manejo sanitário inadequado das instalações, não só afeta a saúde dos animais, como também dificulta o manejo reprodutivo e nutricional resultando na baixa produtividade. A retirada do esterco é realizada uma vez por mês ou quando está em excesso, alguns produtores vendem $\mathrm{o}$ esterco por $\mathrm{R} \$ 2,50$ o saco de $40 \mathrm{~kg}$ e outros apenas juntam em um ambiente afastado do curral.

A reprodução é feita através de monta natural, onde o reprodutor vive o tempo todo junto com as fêmeas, somente separam as matrizes que estão no terço final da gestação e no início da lactação para evitar que os cabritos sejam pisoteados. A separação dos animais de um rebanho em lotes de acordo com a categoria animal além de facilitar o manejo, também previne ocorrências indesejáveis como coberturas e disseminação de doenças.

Os associados da ACOCAMA têm como principal fonte de renda a caprino e ovinocultura e o cultivo de culturas agrícolas, cujas principais são o milho, o feijão, o sorgo forrageiro, a melancia e a mandioca. As principais raças de caprinos são a Boer, mas em sua maioria são mestiços de Anglo Nubiano e SRD (Sem Raça Definida). Os ovinos são das raças Dorper, Somalis e Santa Inês, mas de maioria mestiça.

Há de se destacar a mestiçagem de caprinos para atendimento da produção de carne e pele como a raça Anglo Nubiano de aptidão leiteira e que segundo produtores fora incentivado a inseminação artificial para melhoramento dos rebanhos caprinos, com sêmen de Anglo Nubiano, na década de 1990 pelo IPA (Instituto Agronômico de Pernambuco) o que causou degeneração produtiva na caprinocultura na região do Sertão do Araripe.

Em relação à comercialização, os criadores reúnem-se e cada um fornece um número de animais para serem vendidos para o abatedouro 
de Parnamirim - PE e Ouricuri - PE, que pelo Programa de Aquisição de Alimentos (PAA) e do Programa Nacional de Alimentação Escolar (PNAE) as prefeituras das duas cidades sertanejas compram as carnes para compor a merenda escolar. Os animais são abatidos com peso vivo médio de $17 \mathrm{~kg}$ e idade variável entre 6 a 12 meses.

\section{Produção Forrageira}

Também foi registrado o potencial forrageiro daquele município pertencente aos associados. A área total de pastagem é de 704,45 ha, sendo 296,2 ha (capim buffel), 276,5(caatinga), 64,0 ha (capim corrente), 29,8 ha (milho), 16,2 ha (palma) 13,0 ha (sorgo), 7,8 ha (capim elefante), 0,5 (cana de açúcar), 0,5 (estilosantes) e 0,5 (leucena). Além dessas culturas, também é cultivado feijão por todos os produtores, sendo utilizado na alimentação humana e os restos da cultura são fornecidos aos animais.

A espécie forrageira mais cultivada pelos associados é o capim buffel (Cenchrus ciliaris L). Segundo Silva et al. (1987), Dantas Neto et al. (2000) o capim buffel é a principal espécie forrageira cultivada no semi árido, esta é uma espécie que incrementa a capacidade de suporte dos sistemas pecuários do semi árido, capazes de suportar as longas estiagens com alta produtividade (Silva et al., 1987).

A segunda espécie mais cultivada é o capim urocloa (Uroclo amosambisencis), que representa 64 ha da produção de forragem dos associados. É também conhecido como capim corrente e é uma gramínea muito apreciada pelos animais, capaz de suportar pastejo próximo ao nível do solo e que aos poucos vem conquistando espaço no semiárido (Almeida et al., 2011).

O capim elefante (Pennisetum purpureum Schum) representa uma área de 7,8 ha pertencentes ao total da área de todos os associados. Esta forrageira pode ser considerada uma das mais importantes na produção de volumosos para a pecuária da região nordestina (Costa et al., 2008). Pelo seu alto potencial produtivo, é uma das poucas forrageiras cultivadas pelos criadores nas áreas úmidas existentes, como baixios, várzeas e áreas próximas de açudes e barreiros. As capineiras de capim elefante são em geral, mal manejadas no Nordeste e são praticamente abandonadas sem manejo, é uma cultura não recomendada para o semiárido, principalmente em regime de sequeiro, já que é uma espécie muito exigente em água.

Uma prática essencial ao manejo nutricional e consequentemente produtivo, no semiárido brasileiro, é a produção de ensilagem, pois de acordo com Evangelista et al. (2004) para produção de silagem de boa qualidade, a forrageira a ser ensilada deve apresentar teor de matéria seca acima de $20 \%$.

A ensilagem deve ser realizada com espécies nativas da caatinga, principalmente nos períodos de estiagem prolongada, que são mais produtivas no período seco, como a faveleira e o marmeleiro, por exemplo, e a exótica algaroba, etc. Segundo Maciel et al. (2004) armazenar forragens de boa qualidade para utilização no período seco significa ir de encontro a um dos principais problemas da exploração pecuária regional, que é a extrema estacionalidade da produção forrageira.

Outra planta de destaque no Semiárido é a palma forrageira (Opuntiaficus indica Mill). Nas duas últimas décadas, consolidou-se como uma das principais forrageiras cultivadas para alimentação de ruminantes (Santos et al., 2004). Esta cactácea constitui um alimento suculento de grande importância para os rebanhos, sobretudo nos períodos de estiagens mais prolongadas. É um alimento de bom valor nutritivo e capaz de suprir grande parte das necessidades de água dos animais (Santos et al., 1997, Albuquerque et al., 2002).

A produção de sorgo forrageiro (Sorghum bicolor Lam. Moench. S. vulgare Pers.) pelos associados de Santa Filomena é de 13,0 ha. Segundo Ribas (2008) O sorgo granífero é o que tem maior expressão econômica e está entre os cinco cereais mais cultivados do mundo.

O milho (Zea mays Lam.) também é uma cultura bastante cultivada pelos produtores associados. A área total de produção de milho equivale a 29,8 ha, sendo utilizado tanto na alimentação humana quanto na alimentação animal. Dependendo do rendimento da cultura, o milho torna-se uma fonte de renda, beneficiando os produtores com a sua venda no comércio local ou na associação.

A área de produção de Leucena pertencente aos associados é de apenas 0,5 ha. A Leucena (Leucaena leucocephala Lam.) é uma leguminosa perene de porte arbustivo a arbóreo, capaz de se adaptar as condições de baixa 
pluviosidade (Silva, 1992). Segundo Ramos et al. (1997) a leucena produz forragem de boa qualidade, rica em proteína e com teores de minerais capazes de atender as exigências nutricionais dos animais, podendo ser fornecida no cocho (fresca, fenada ou ensilada), como banco de proteína ou em consórcio com gramíneas.

Os associados não adotam as práticas adequadas de manejo em nenhuma das pastagens cultivadas, verificando-se a superlotação da mesma, a falta de divisão das áreas para rotação das pastagens e o cultivo sem adubação e calagem, resultando na degradação das áreas de pastagem. O manejo correto destas áreas, além de evitar sua degradação, melhora a qualidade da forragem e, consequentemente, aumenta a produção do rebanho.

Os produtores associados possuem uma área total de 276,5 ha de caatinga, sendo utilizada como fonte alimentar para o rebanho, principalmente os caprinos e ovinos. Na maioria das propriedades os animais são soltos na caatinga pela manhã e recolhidos no final da tarde, se alimentando apenas da vegetação local é a forma tradicional de criar animais no semiárido, sem planejamento zootécnico. Segundo Araújo Filho \& Carvalho (1997) na caatinga nativa os índices de desempenho animal são muitos baixos, sendo necessários 1,4 a 1,5 ha para criar um ovino ou um caprino durante um ano, com uma produção de peso vivo animal de $20 \mathrm{~kg} / \mathrm{ha}$.

Em termos de capacidade de suporte, na caatinga rebaixada são necessários de 0,5 a 0,7 ha para manter uma cabeça de caprino por ano (Araújo Filho et al., 1999). Poucos produtores fornecem ração concentrada, ou outros ingredientes como farelo de milho, raspa de mandioca, cana de açúcar picada ou o bagaço, palma forrageira picada e triturada e sal mineral. Os animais se alimentam todos juntos, sem haver separação dos animais por categorias, outros colocam os animais para se alimentar da pastagem e capineiras disponíveis como, capim elefante, buffel e capim corrente.

\section{Manejo do solo}

Não há nenhum acompanhamento de manejo de fertilidade de solo, e inclusive ainda é prevalente a utilização de queimadas para a limpeza das áreas agricultáveis. As análises da fertilidade de solo foram realizadas para subsidiar possíveis intervenções técnicas junto aos produtores, pois somente os dados obtidos a campo pela observação visual não são suficientes para se determinar possíveis problemas relacionados à nutrição das plantas. O conhecimento da fertilidade do solo permite a utilização de práticas mais confiáveis de manejo de corretivos e fertilizantes (Malavolta, 2006).

Os teores de potássio no solo foram baixos, pois variaram de 0,24 a $0,39 \mathrm{cmol}_{\mathrm{c}} / \mathrm{dm}^{-3}$, sendo indicado para os solos de Pernambuco o teor médio de 1,2 a 2,3 $\mathrm{cmol}_{\mathrm{c}} / \mathrm{dm}^{-3}$ (Malavolta, 2006).

O cálcio, em todas as propriedades apresentou teores com variações de 2,2 a $7,5 \mathrm{cmolc} / \mathrm{dm}^{3}$, considerados de médio $\left(2-4 \mathrm{cmolc} / \mathrm{dm}^{3}\right)$ a alto (quando maior do que $4 \mathrm{cmolc} / \mathrm{dm}^{3}$ (Tomé Junior, 1997). Segundo Santos et al. (2004) os solos do semiárido são, quase sempre, bem supridos de cálcio. A baixa precipitação e pequena lavagem a que estão sujeitos contribuem para isso. O cálcio é um macro nutriente essencial às culturas, que tem muitos efeitos no crescimento e desenvolvimento da planta. O magnésio apresentou teores variando de 1,2 a 3,6 cmolc/dm ${ }^{3}$, considerados altos por Tomé Junior (1997) devido ter concentração superior a 0,8 $\mathrm{cmolc} / \mathrm{dm}^{3}$.

A maioria dos produtores associados à ACOCAMA não tem conhecimento da importância da fertilidade dos solos para a agricultura, o cultivo agrícola nessas propriedades são realizados de forma inadequada, por falta de conhecimento e condições financeiras em contratarem assistência técnica para auxiliá-los no manejo do solo, principalmente na adubação e calagem, que são as principais práticas realizadas sem orientação de um profissional qualificado na área.

Segundo Malavolta (2006) uma adubação correta começa com a análise do solo, continua com a correção da acidez quando necessário e termina com a aplicação correta do adubo. Os produtores não fazem nem mesmo a análise de solo nas propriedades, que é uma prática rápida, simples e barata, custando em média $\mathrm{R} \$ 45,00$ por cada amostra. Apenas alguns dos associados conhecem essa importância, mas não realizam as práticas de manejo adequadas para melhorar a fertilidade dos solos, por falta de incentivo e organização da Associação.

Os criadores associados não adotam as práticas adequadas de manejo em nenhuma das pastagens cultivadas acima citadas, verificando- 
se a superlotação da mesma, a falta de divisão das áreas para rotação das pastagens e o cultivo sem adubação e calagem, resultando na degradação das áreas de pastagem.

O manejo correto destas áreas, além de evitar sua degradação, melhora a qualidade da forragem e, consequentemente, aumenta a produção do rebanho. É importante utilizar forragens adaptadas às condições geoclimáticas do semiárido e reduzir o quantitativo de forragens exigentes em água oriundas das regiões úmidas do país.

Além de não utilizar adequadamente as fontes alimentares disponíveis no Sertão do Araripe, onde estão inseridos os municípios de Santa Filomena e Ouricuri, como os subprodutos do cultivo da mandioca (Manihot sculenta, Crantz) que é muito produzida na região para a produção de farinha, a maniçoba (Manihot glaziovii, Muell) que é nativa e só pode ser fornecida fenada ou ensilada porque no processo perde a sua toxidez (ácido cianídrico).

Os produtores não realizam o estoque de alimentos através da ensilagem e fenação durante o período chuvoso, isso é um grande contribuinte para a deficiência da caprino-ovinocultura da região, mesmo a atividade apresentando grande potencial no nordeste brasileiro por possuir a maior população de caprinos e ovinos do Brasil. Não realizam o cultivo irrigado de nenhuma das culturas cultivadas por eles, apenas o capimelefante é cultivado próximo aos barreiros e açudes da propriedade e nem realizam adubação nem calagem dos solos.

\section{Conclusão}

Um dos principais problemas dos caprinoovinocultores associados à ACOCAMA, em Ouricuri-PE e em Santa Filomena-PE, é a falta de conhecimento técnico para escolher e utilizar as espécies forrageiras, cultivá-las, colhê-las e aplicar as técnicas de alimentação e conservação de alimentos como fenação e ensilagem, pouco utilizado pelos produtores como estratégias de convivência com a seca.

Há a valorização de espécies forrageiras não adaptadas às condições climáticas do semiárido, como o capim-elefante e a cana-de-açúcar, em detrimento da utilização, e consequente valorização das espécies próprias à região como a palma forrageira e leucena.
Faz-se necessário o investimento em educação agrotécnica e zootécnica aos caprinoovinocultores. Os resultados apresentados fortalecem os dados de que a pecuária no semiárido se constitui como economia de subsistência, de caráter extensivo, com baixo controle zootécnico, que pôde ser observado na proporção inadequada de matrizes para demais animais nas outras fases produtivas e na proporção de reprodutores para matrizes.

O que evidencia a necessidade de práticas extensionistas de capacitação técnica na área de caprino e ovinocultura para os criadores associados.

Para a ACOCAMA é necessário maior planejamento $\mathrm{e}$ atendimento às necessidades técnicas dos produtores que perpassa pela contratação de profissionais das Ciências Agrárias como Zootecnistas, Agrônomos e Veterinários para planejamento produtivo e assistência técnica.

\section{Agradecimentos}

À Associação de Criadores de Ovinos e Caprinos da Microrregião do Araripe (ACOCAMA) pela parceria de cooperação e apoio.

\section{Referências}

Albuquerque, S. S. C., Lira, M. A., Santos, M. d., Dubeux Jr, J. C. B., Melo, J. N., Santos, D. C. \& Farias, I. (2002). Utilização de três fontes de nitrogênio associadas à palma forrageira (Opuntia ficusindica, Mill.) cv. Gigante na suplementação de vacas leiteiras mantidas em pasto diferido. Revista Brasileira de Zootecnia, 31, 1315-1324.

Almeida, P. J. P., Azevedo, S. T., Alves, E. M., Souza, D. R., Santos, A. B., Pereira, T. C. J. \& Pedreira, M. S. (2011). Fontes energéticas suplementares para ovinos Santa Inês em pastagens de capim urocloa na época seca. Revista Brasileira de Saúde e Produção Animal, 12, 140-154.

Araújo Filho, J. A. \& Carvalho, F. C. (1997). Desenvolvimento sustentável da caatinga. Sobral: EMBRAPACNPC, 1, 1-17.

Araújo Filho, J. A., Carvalho, F. C. \& Silva, N. L. (1999). Criação de ovinos a pasto no semiárido nordestino. Sobral: Embrapa Caprinos, 1, 143-149. 
Araújo, M. J. (2003). Fundamentos de agronegócios. Editora Atlas SA.

Costa, R., Almeida, C., Pimenta Filho, E., Holanda Júnior, E. \& Santos, N. (2008). Caracterização do sistema de produção caprino e ovino na região semi-árida do estado da Paraíba, Brasil. Archivos de Zootecnia, 57, 195-205.

COPAM-MG - Conselho Estadual de Política Ambiental -. Deliberação Normativa $\mathrm{N}^{\circ} 74$, de 09 de Setembro de 2004. Diário do Executivo do Estado das Minas Gerais.

Costa, V. M. M., Simões, S. V. D. \& RietCorrea, F. (2011). Controle das parasitoses gastrintestinais em ovinos e caprinos na região semiárida do Nordeste do Brasil. Pesquisa Veterinaria Brasileira, 31, 65-71.

Dantas Neto, J., Silva, J. F. A. S., Furtado, D. A. \& Matos, J. A. (2000). Influência da precipitação e idade da planta na produção e composição química do capim-buffel. Pesquisa Agropecuária Brasileira, 35, 18671874.

Delgado, G. C. (2004). O setor de subsistência na economia e na sociedade brasileira: gênese histórica, reprodução e configuração contemporânea. Instituto de Pesquisa Econômica Aplicada, Brasília 30p.

EMBRAPA. (2006). Sistema brasileiro de classificação de solos.

Evangelista, A. R., Peron, A. J. \& Amaral, P. N. C. (2004). Forrageiras não convencionais para silagem-mitos e realidades. Simpósio sobre manejo estratégico da pastagem, 2, 463-507.

FAO. (2015). Statistical Yearbook. Food and Agriculture Organization of the United Nations, Rome, Italy.

Gouveia, A. M. G. (2003). Aspectos sanitários da caprino-ovinocultura no Brasil. Simpósio internacional de caprinos e ovinos de corte, 2.

Jainudeen, M., Wahid, H. \& Hafez, E. (2004). Ovinos e caprinos. In: Hafez, E. S. E. \& Hafez, B. (eds.) Reprodução Animal. Manole, São Paulo.

Kunzller, M. T. \& Bulgacov, S. (2011). As estratégias competitivas e colaborativas e os resultados individuais e coletivos no associativismo rural em Quatro Pontes (PR). Revista de Administração Pública, 45, 363393.
Maciel, F. C., Lima, G. F. C., Guedes, F. X., Medeiros, H. R. \& Garcia, L. R. U. C. (2004). Silo de superfície - segurança alimentar dos rebanhos na seca. in: Armazenamento de forragens para agricultura familiar. Empresa de Pesquisa Agropecuária do Rio Grande do Norte, 1, 24-27.

Malavolta, E. (2006). Manual de nutrição mineral de plantas. Agronômica Ceres, São Paulo.

Medeiros, L. P., Girão, R. N., Girão, E. S., Pimentel, J. C. M. (1994). Caprinos: princípios básicos para sua exploração. Teresina: Empresa Brasileira de Pesquisa Agropecuária - Embrapa, Centro de Pesquisa Agropecuária do Meio-Norte, 177 p.

Olander, HJ, Santa Rosa, J., Vieira, L., Berne, M. \& Brown, C. (1989). Herd health management of goats in the semiarid tropics.

Oliveira, J., Braga, E., Dias, P., Zacharias, F., Maranhão, A., Mendes, P. \& Moura Filho, B. (1995). Avaliação da adoção das tecnologias usadas pelos produtores de caprinos e de ovinos tropicais dos Estados da Bahia, Piauí, Pernambuco e Ceará. Encontro da Sociedade Brasileira de Sistemas de Produção, 2, 128147.

Oliveira, J. C. V., Rocha, L. L., Ribeiro, M. N. \& Gomes Filho, M. A. (2006). Caracterização e perfil genético visível de caprinos Nativos no Estado de Pernambuco. Archivos de Zootecnia, 55, 63-73.

Pedrosa, K. I. F., Barreto Jr., R. A., Costa, E. S., Leite, A. I., Paula, V. V. (2003). Aspectos epidemiológicos das criações de caprinos na zona noroeste do Rio Grande do Norte. Revista Caatinga, 16, 17-21.

Pinheiro, R. R., Gouveia, A. M. G., Alves, F. S. F., Haddad, J. P. A. (2000). Aspectos epidemiológicos da caprinocultura cearense. Arquivo Brasileiro de Medicina Veterinária e Zootecnia, 52:5, 534-543.

Prado, D. E. (2003). As caatingas da América do Sul. Ecologia e conservação da Caatinga, 2, 3-74.

Ramos, G., Italiano, E., Nascimento, M. \& Araujo Neto, R. (1997). Recomendações sobre o cultivo e uso da leucena na alimentação animal. EMBRAPA-CPAMN. 
Ribas, P. (2008). Cultivo do sorgo. Importância econômica. Sistemas de Produção, 2, 3.

Santos, A., Ferreira, G., Xavier, R., Ferreira, M., Severino, L., Beltrão, N., Dantas, J. \& Moraes, C. (2004). Deficiência de cálcio e magnésio na mamona (Ricinus communis L.): descrição e efeito sobre o crescimento e a produção da cultura. Congresso Brasileiro de Mamona.

Santos, D., Farias, I., Lira, M., Tavares Filho, J., Santos, M. \& Arruda, G. (1997). A palma forrageira (Opuntia ficus-indica Mill $e$ Nopalea cochenillifera Salm-Dyck) em Pernambuco: cultivo e utilização. IPA, Recife.

Silva, C. (1992). Avaliação do gênero Leucaena na região semi-árida de Pernambuco, Recife.

Silva, C. M. M. S., Oliveira, M. C. \& Severino, G. (1987). Avaliação da produtividade de treze cultivares de capim buffel, na região semi-árida de Pernambuco. Pesquisa Agropecuária Brasileira, 22, 513-520.

Silva, D., Silva, A., Lima, A. \& Melo, J. (2004). Exploração da caatinga no manejo alimentar sustentável de pequenos ruminantes. Congresso Brasileiro de Extensão Universitária.

Sotomaior, C. S., Carli, L. M., Tangleica, L., Kaiber, B. K. \& Souza, F. P. (2007). Identificação de ovinos e caprinos resistentes e susceptíveis aos helmintos gastrintestinais. Revista Acadêmica, 5, 397-412.

Tomé Junior, J. B. (1997). Manual para interpretação de análise de solo. Livraria e Editora Agropecuária.

Recebido em Janeiro 16, 2015

Aceito em Fevereiro 12, 2016

License information: This is an open-access article distributed under the terms of the Creative Commons Attribution License, which permits unrestricted use, distribution, and reproduction in any medium, provided the original work is properly cited 